\title{
Diel vertical migration of larval and early-juvenile burbot optimises survival and growth in a deep, pre-alpine lake
}

\author{
MICHAEL THOMAS DONNER AND REINER ECKMANN \\ Limnological Institute, University of Konstanz, Konstanz, Germany
}

\begin{abstract}
SUMMARY
1. Burbot larvae (Lota lota) perform a substantial diel vertical migration (DVM) of increasing amplitude in the pelagic zone during a 3-month period before migrating to the littoral zone as early-juveniles. We hypothesised that feeding in the warm surface layers at night and then spending the day in cold water below the thermocline reduces metabolic costs and earns burbot larvae an energetic advantage.

2. To test our hypothesis, we mimicked the temperature conditions experienced by vertically migrating burbot in the pelagic zone. We also simulated three further scenarios, in which temperature remained constant.

3. Burbot showed the best performance (defined as specific growth rate multiplied by the probability of survival) in the treatments simulating DVM. The high temperature treatment, simulating permanent residence in the warm epilimnion, resulted in high growth combined with high mortality. At a permanently low temperature, simulating life in the hypolimnion, growth was poor and activity reduced.

4. In a deep, temperature-stratified lake, where the apparently beneficial overall medium temperature is found in a restricted layer within the thermocline, DVM optimises performance in young burbot. Various ultimate factors might act synergistically in selecting for DVM in larval and early-juvenile burbot.
\end{abstract}

Keywords: bioenergetic efficiency, DVM, Lota lota, mortality, performance

\section{Introduction}

Diel patterns in the behaviour of fish are common (Helfman, 1993) and often appear as rhythmic vertical movements, whereby fish commute daily between the surface and the hypolimnion, a phenomenon defined as diel vertical migration (DVM) (Levy, 1987). Such migration is observed in many aquatic organisms, including phytoplankton (Sommer \& Gliwicz, 1986), zooplankton (Young \& Yan, 2008; Semyalo, Nattabi \& Larsson, 2009), jellyfish (Dupont et al., 2009), bony fish (Cech et al., 2005; Mehner, Kasprzak \& Hölker, 2007; Adams et al., 2009) and sharks (Weng \& Block, 2004;

Correspondence: Michael Thomas Donner, Limnological Institute, University of Konstanz, 78457 Konstanz, Germany. E-mail: mtdonner@googlemail.com
Sims et al., 2006). In fish, DVM is often restricted to specific life stages, wherein only larval (Yamashita, Kitagawa \& Aoyama, 1985; Voss, Schmidt \& Schnack, 2007), juvenile (Schabetsberger et al., 2000) or late juvenile and adult fish (Eckmann \& Imbrock, 1996; Hrabik et al., 2006) show this behaviour. This is in contrast to zooplankton, where DVM is typically undertaken throughout life. The diel light cycle is generally considered to be the proximate factor that triggers DVM (Helfman, 1993), and light intensity plays an important role in DVM, in combination with one or more ultimate factors (e.g. Appenzeller \& Leggett, 1995; Hurst et al., 2009).

Several ultimate factors have been implicated in the regulation of DVM, all potentially resulting in daily movements in the same direction. Thus, different hypotheses about the adaptive value of DVM are not 
mutually exclusive. The 'antipredation window' hypothesis (Clark \& Levy, 1988; Scheuerell \& Schindler, 2003) combines two ultimate factors for DVM, namely the pursuit of food and the avoidance of predators. Vertical movements of fish following the migration of their preferred prey are well documented, for example that of sockeye salmon (Oncorhynchus nerka Walbaum) in Alaskan lakes (Scheuerell \& Schindler, 2003) or of sprat (Sprattus sprattus Linnaeus) in the Baltic Sea (Voss et al., 2007), both in pursuit of zooplankton. Daily vertical migration as a mean of avoiding visually oriented predators has been described for fish (Levy, 1987; Hrabik et al., 2006) as well as for zooplankton (De Robertis, Jaffe \& Ohman, 2000), whereby prey species remain in deeper and darker water layers during the day and migrate to the surface at dusk, when the risk of predation decreases with fading light intensity.

This hypothesis aside, DVM has also been discussed in relation to energy efficiency in aquatic organisms (Clark \& Green, 1991). In poikilothermic organisms, growth, food consumption and food conversion are temperature dependent (Schmidt-Nielson, 1997), and thus a retreat to cooler water during nonfeeding periods, or when food is limited, may reduce metabolic rate and aid energy conservation (Brett, 1971). Digestion requires less energy at low temperature, making the assimilation of food more efficient in cool conditions (Hofmann \& Fischer, 2003). On the other hand, gut evacuation rate in fish increases exponentially with increasing temperature (Persson, 1982). Neverman \& Wurtsbaugh (1994) demonstrated that gut evacuation placed a limit on growth on the sculpin Cottus extensus (Bailey and Bond). The enhanced rate of gut evacuation in warm water was such that a DVM cycle resulted in growth three times faster than that achieved in permanently cool conditions, and thus in this fish, DVM maximises energy intake by exploiting thermal gradients (Wurtsbaugh \& Neverman, 1988). The energetic benefits of hunting in warm water, then digesting and resting in cooler water, have also been described for the benthic shark (Scyliorhinus canicula Linnaeus) (Sims et al., 2006), where a DVM reduced daily energy costs by about $4 \%$.

Lake Constance, a deep oligotrophic pre-alpine lake is the core distribution range of burbot (Lota lota (Linnaeus, 1758)) in southern Germany (Schneider, Lelek \& Korte, 2002). Burbot in the lake spawn from
January to March at depths of between 60 and $100 \mathrm{~m}$ (Hirning, 2006). The sinking eggs develop on the bottom at $4-5^{\circ} \mathrm{C}$ and larvae hatch after $120-160$ degree-days (Donner, unpublished data). During the first 2 weeks of life, the larvae swim to the surface to fill their swim bladder. They grow in the pelagic zone for about 3 months (Wang \& Appenzeller, 1998), before switching to a benthic way of life in the littoral zone as early-juveniles (Fischer, 1999). Sampling with ichthyoplankton nets (Wang \& Appenzeller, 1998) and hydroacoustic surveys by day and night, Probst \& Eckmann (2009b) have shown that larval and earlyjuvenile burbot migrate with increasing amplitude from near the surface at night down to a maximum depth of $70 \mathrm{~m}$ during the day for about 3 months, prior to making a permanent shift to the littoral zone (Miler \& Fischer, 2004). In Lake Constance, DVM behaviour begins with the onset of lake stratification in spring, when surface water temperature exceeds $10{ }^{\circ} \mathrm{C}$.

Previous field studies of the early life history of burbot in Lake Constance have shown that light is the proximate factor controlling DVM and that the observed migration patterns support the antipredation window hypothesis (Probst \& Eckmann, 2009b). Here, we focussed on the bioenergetic implications of DVM and hypothesised that larval and early-juvenile burbot gain an energetic benefit through this behaviour. We expected that the fish would grow faster under temperature regimes mimicking DVM, compared to those simulating conditions encountered as a result of other behaviour that fish might adopt in a deep lake with a temperature-stratified pelagic zone.

\section{Methods}

We obtained burbot larvae by means of captive breeding. Adult male and female burbot spawned readily in outdoor tanks, from which the eggs were collected immediately after spawning and incubated in 10-L jars at $4{ }^{\circ} \mathrm{C}$ until hatching. First-feeding larvae were fed ad libitum with newly hatched Artemia sp. nauplii three to five times per day until the beginning of the experiment. The larvae were kept in 100-L stock tanks under a consistent light : dark cycle (12 h : $12 \mathrm{~h}$; including $1 \mathrm{~h}$ of dusk and $1 \mathrm{~h}$ of dawn). The illumination strength was 1000 lux during day and 0.002 lux at night. Illumination strength increased/ decreased linearly to day or night values during dawn 
and dusk, respectively. Water temperature was gradually increased from $4{ }^{\circ} \mathrm{C}$ to $12{ }^{\circ} \mathrm{C}$ over 10 days, and these conditions were the same for all fish used in the different treatments.

To test our hypothesis, we developed a special recirculation system to investigate the influence of different temperature regimes on the growth of larval and early-juvenile burbot. The system comprised 15 aquaria $(20 \mathrm{~L}$ each) in which five different treatments (each with three replicates) could be carried out in parallel. Temperatures were maintained by precisely regulating the inflow of cooled or heated water into each aquarium. We simulated five different temperature regimes, each mimicking a different strategy potentially available to larval and early-juvenile burbot (Table 1): warm - representing permanent residence in the epilimnion; cold - residing permanently below the thermocline in the hypolimnion; medium - the average of the warm and cold treatments, to represent an intermediate habitat; DVM - cold by day and warm at night; and finally reverse DVM - warm by day and cold at night. The temperatures in the aquaria were closely monitored during both experiments (Table 1), and fluctuations in the constant temperature treatments did not exceed $1.0^{\circ} \mathrm{C}$. In the last 5 days of the second experiment, however, the temperature increased from $12{ }^{\circ} \mathrm{C}$ to $14.4{ }^{\circ} \mathrm{C}$ in the medium treatment because of a general warming of the laboratory. The increases and decreases in temperature used to mimic vertical migration in both the DVM and the reverse DVM treatments took place over $2 \mathrm{~h}$, close to the time window in which larval and early-juvenile burbot complete their dawn and dusk migrations in the field (Probst \& Eckmann, 2009b). The mean temperature during the cold phase (simulating hypolimnetic conditions) was about $5{ }^{\circ} \mathrm{C}$, rising to about $19^{\circ} \mathrm{C}$ during

Table 1 Temperature profile for the five temperature treatments of Experiments I (early larvae) and II (late larvae)

\begin{tabular}{|c|c|c|c|c|}
\hline \multirow[b]{2}{*}{ Treatment } & \multicolumn{2}{|c|}{ I (early larvae) } & \multicolumn{2}{|c|}{ II (late larvae) } \\
\hline & Day & Night & Day & Night \\
\hline Warm & \multicolumn{2}{|c|}{$19.0 \pm 0.4$} & \multicolumn{2}{|c|}{$19.2 \pm 0.5$} \\
\hline DVM & $5.3 \pm 0.2$ & $19.0 \pm 0.5$ & $5.8 \pm 0.3$ & $19.2 \pm 0.4$ \\
\hline Reverse DVM & $18.9 \pm 0.2$ & $5.3 \pm 0.2$ & $19.3 \pm 0.3$ & $5.6 \pm 0.3$ \\
\hline Medium & \multicolumn{2}{|c|}{$12.1 \pm 0.3$} & \multicolumn{2}{|c|}{$13.0 \pm 1.1$} \\
\hline Cold & \multicolumn{2}{|c|}{$5.1 \pm 0.2$} & \multicolumn{2}{|c|}{$5.3 \pm 0.2$} \\
\hline
\end{tabular}

Temperature is given in degrees Celsius as mean \pm SD. DVM, diel vertical migration. the warm phase (representing epilimnetic conditions). During dusk and dawn one-third of the water was exchanged by discarding the outflow of the aquaria and adding fresh water to the heating and cooling units.

Burbot were fed with newly hatched Artemia nauplii directly before the onset of the dusk phase in all treatments, a regime that reflected the natural feeding pattern observed in Lake Constance (Probst \& Eckmann, 2009b). Daily food rations of about 200 Artemia nauplii per larval burbot had been estimated in a separate study, and therefore, larvae were fed with a daily ration of 1500-2000 nauplii per individual to ensure ad libitum feeding. The food was retained in each aquarium by $250-\mu \mathrm{m}$ sieves at the outflow. Two successive experiments took place, Experiment I (early larvae) started 31 days post-hatch and Experiment II (late larvae) started 55 days post-hatch. Experiments I and II lasted for 15 and 25 days, respectively. Each aquarium was stocked with 80 (Expt I) and 100 (Expt II) burbot selected at random. Dead larvae were removed and counted daily. Samples of 10 fish from each aquarium were taken every 5 days and frozen in $0.64 \% \mathrm{NaCl}$ solution at $-80{ }^{\circ} \mathrm{C}$ for subsequent analyses. Standard length (SL mm) was determined from measurements of 30 freshly thawed burbot per treatment, using the digital image analysis software, ImageJ 1.41 (Wayne Rasband, Open Source). Mean wet mass was calculated from 30 burbot per treatment, weighed to the nearest $0.01 \mathrm{mg}$. The specific growth rate (SGR) in terms of wet mass was calculated according to Ricker (1979) as SGR $=(\ln$ (final body weight of fish) $-\ln$ (initial body weight of fish)) day ${ }^{-1} \times 100$. To evaluate the combined effects of the different temperature treatments on growth and survival of burbot during our shortterm experiments, we defined an index of performance as specific growth rate multiplied by the probability of survival in the experiment: performance $=$ probability of survival $\times \mathrm{SGR} \times \mathrm{day}^{-1}$. The statistical analysis software JMP7 (S.A.S.) was used for all calculations. Replicates were treated as random factors in analyses of variance.

\section{Results \\ Survival}

In the low temperature treatments, burbot were inactive and suffered low mortality, attaining survival 

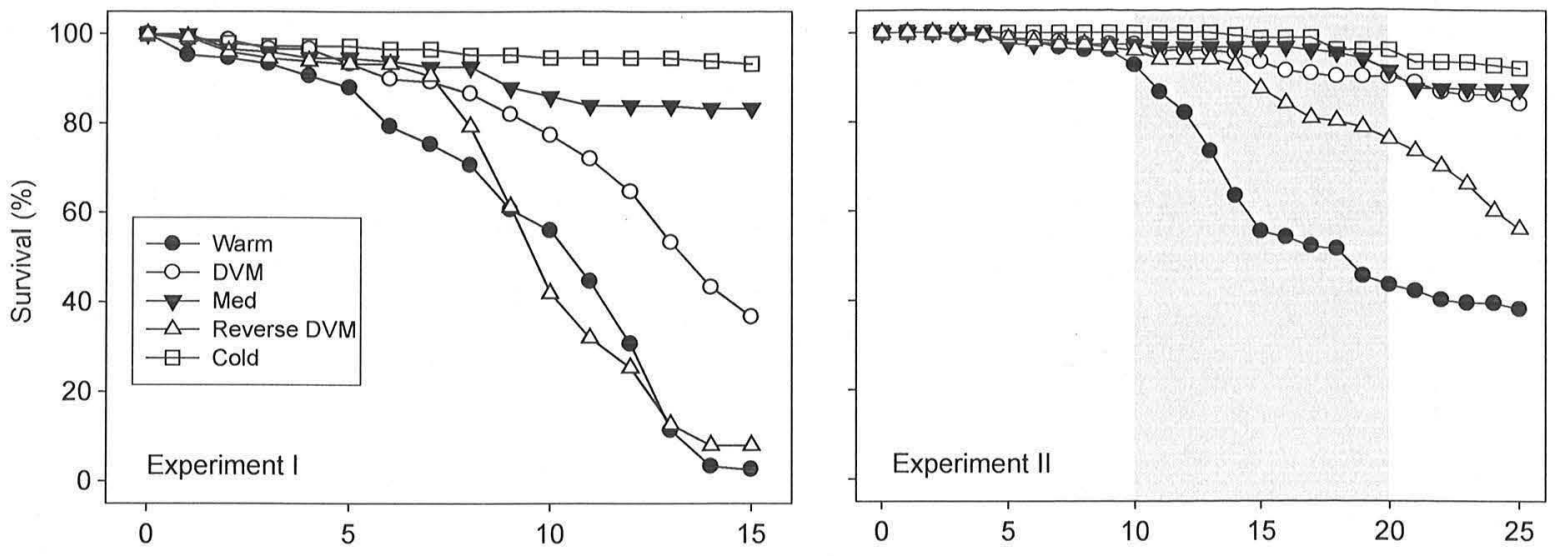

Day of experiment

Fig. 1 The mean survival (\%) of burbot over the course of Experiment I and II. The shaded area in the right figure marks the time window for metamorphosis of burbot.

rates $( \pm \mathrm{SD})$ of $93.3 \pm 6.1 \%$ in Experiment $\mathrm{I}$ and $92.0 \pm 8.7 \%$ in Experiment II (Fig. 1). Survival in the medium temperature treatment was similar in both experiments, at $81.3 \pm 8.1 \%$ (Expt I) and $87.3 \pm 1.2 \%$ (Expt II). In the DVM treatment, final survival rates of $36.7 \pm 5.0 \%$ (Expt I) and $84.0 \pm 5.3 \%$ (Expt II) were found. In Experiment II, there was no significant difference in survival (ANOvA, Tukey-Kramer HSD, $P<0.05$ ) between the DVM and medium temperature treatments. In the warm and reverse DVM treatments, survival was significantly lower (ANOVA, TukeyKramer HSD, $P<0.05$ ) than that recorded for the DVM treatments in both experiments. Metamorphosis was observed in Experiment II between day 10 and day 20 , by which time more than $90 \%$ of sampled fish in all treatments had metamorphosed (metamorphosis defined as: fully separated dorsal fin, visible barbel, full pigmentation).

\section{Growth}

Burbot SL ( $\mathrm{mm} \pm \mathrm{SD}$ ) at the end of both experiments differed significantly (two-way ANOVA, Tukey-Kramer HSD, $P<0.001$ ) between treatments (Table 2). Burbot grew largest in the warm treatment, reaching $17.8 \pm 1.5 \mathrm{~mm}$ SL at the end of Expt I and $29.3 \pm 3.4 \mathrm{~mm}$ SL by the end of Expt II. In the DVM treatment, burbot grew to a final standard length of $13.8 \pm 1.6 \mathrm{~mm}$ and $27.7 \pm 2.7 \mathrm{~mm}$ in Experiments I and II, respectively. At the end of Experiment II, there

Table 2 Growth of burbot as standard length (SL mm \pm SD) at the start of the experiments $(n=30)$ and at the sampling days $(n=30$ per treatment)

\begin{tabular}{|c|c|c|c|c|c|c|c|c|c|c|c|}
\hline \multirow{3}{*}{$\frac{\text { Experiment }}{\text { I early larvae }}$} & \multicolumn{11}{|c|}{ Treatment } \\
\hline & \multirow{2}{*}{$\begin{array}{c}\text { Day } \\
0\end{array}$} & \multicolumn{2}{|l|}{ Warm } & \multicolumn{2}{|l|}{ DVM } & \multicolumn{2}{|l|}{ Medium } & \multicolumn{2}{|c|}{ Reverse DVM } & \multicolumn{2}{|l|}{ Cold } \\
\hline & & & & & & $7.5 \pm 1.1$ & & & & & \\
\hline & 5 & $10.3 \pm 0.9$ & A & $9.6 \pm 1.0$ & B & $9.6 \pm 0.6$ & B & $9.0 \pm 1.1$ & B & $8.4 \pm 0.6$ & \\
\hline & 10 & $13.4 \pm 1.8$ & A & $11.5 \pm 0.9$ & B & $10.7 \pm 1.3$ & $B C$ & $10.1 \pm 1.0$ & $\mathrm{C}$ & $8.6 \pm 0.8$ & D \\
\hline & 15 & $17.8 \pm 1.5$ & A & $13.8 \pm 1.6$ & B & $13.1 \pm 1.3$ & $\mathrm{BC}$ & $12.4 \pm 1.2$ & $\mathrm{C}$ & $9.3 \pm 1.0$ & D \\
\hline \multirow[t]{6}{*}{ II late larvae } & 0 & & & & & $12.1 \pm 1.7$ & & & & & \\
\hline & 5 & $17.4 \pm 1.7$ & A & $16.1 \pm 1.5$ & B & $15.1 \pm 0.9$ & BC & $14.5 \pm 1.6$ & $\mathrm{C}$ & $13.2 \pm 1.5$ & D \\
\hline & 10 & $20.5 \pm 2.0$ & A & $18.8 \pm 1.4$ & B & $17.3 \pm 1.6$ & C & $15.9 \pm 2.0$ & D & $13.9 \pm 1.2$ & $\mathrm{E}$ \\
\hline & 15 & $23.9 \pm 2.3$ & A & $21.6 \pm 2.4$ & B & $19.9 \pm 1.9$ & C & $18.9 \pm 2.1$ & C & $14.8 \pm 1.9$ & D \\
\hline & 20 & $28.0 \pm 3.5$ & A & $23.4 \pm 2.4$ & B & $21.8 \pm 2.3$ & B & $19.9 \pm 2.7$ & C & $15.7 \pm 1.6$ & $\mathrm{D}$ \\
\hline & 25 & $29.3 \pm 3.4$ & A & $27.7 \pm 2.7$ & A & $24.4 \pm 2.6$ & B & $21.6 \pm 2.5$ & C & $16.9 \pm 2.5$ & D \\
\hline
\end{tabular}

Different letters indicate significant differences between the treatments (two-way ANOVA, Tukey-Kramer HSD, $P<0.001$ ). DVM, diel vertical migration. 


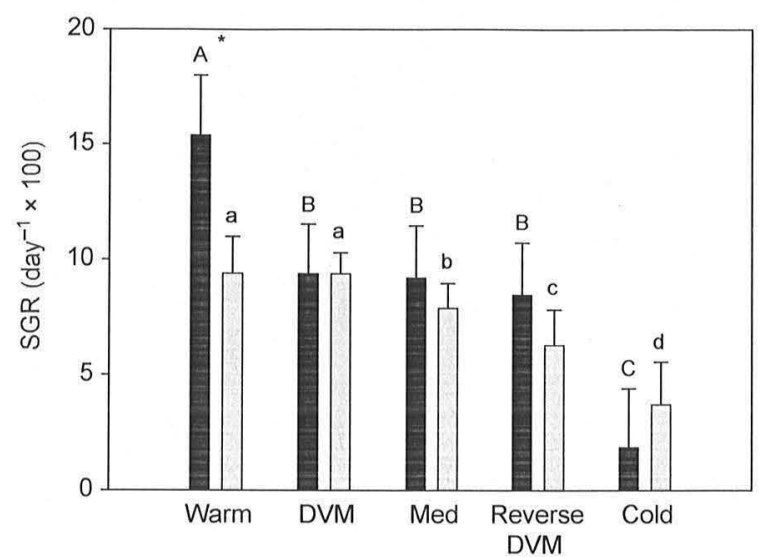

Fig. 2 Specific growth rates (SGR) of burbot (mean \pm SD) for Experiment I ( $n=30$ per treatment, dark bars) and II $(n=30$ per treatment, grey bars). Asterisk indicate significant differences between experiments for a specific temperature treatment (t-test, $P<0.05)$. Different capital letters indicate significant differences in SGR between burbot treatments for Experiment I, and small letters mark significant differences between burbot treatments for Experiment II (all comparisons: two way ANOVA, Tukey-Kramer HSD, $P<0.001$ ).

was no significant difference in SL (two-way ANOVA, Tukey-Kramer HSD, $P<0.001$ ) between fish in the DVM and warm treatments. The medium and reverse DVM treatments ranked next, and growth was significantly lowest in the cold treatment, with final SL of $9.3 \pm 1.0 \mathrm{~mm}$ (Expt I) and $16.9 \pm 2.5 \mathrm{~mm}$ (Expt II), respectively.

In Experiment I, SGR $( \pm S D)$ in terms of wet mass was highest in the warm treatment, while results for the DVM, medium and reverse DVM treatments were lower but not significantly different from each other (Fig. 2). SGR in the warm treatment (9.41 \pm 1.57 day $^{-1}$ ) was significantly lower in Experiment II than in Experiment I, but did not differ significantly from that of the DVM treatment $\left(9.39 \pm 1.49\right.$ day $\left.^{-1}\right)$ (two-way ANOva, Tukey-Kramer HSD, $P<0.001$ ). The medium and reverse DVM treatments ranked second and third in this experiment, while burbot in the cold treatments achieved least growth in both experiments.

\section{Performance}

In Experiment I, burbot in the medium temperature treatment exhibited the best performance $( \pm S D)$ (twoway ANOVA, Tukey-Kramer HSD, $P<0.001)$, whereas the least performance was observed for the

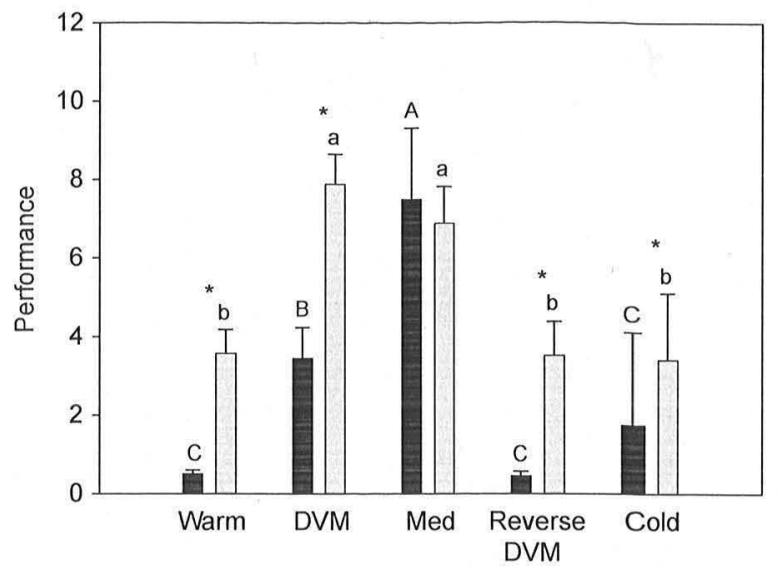

Fig. 3 Performance of burbot (mean \pm SD) for Experiment $I$ ( $n=30$ per treatment, dark bars) and II ( $n=30$ per treatment, grey bars). Asterisks indicate significant differences between experiments for a specific temperature treatment (t-test, $P<0.05$ ). Different capital letters indicate significant differences in Performance between burbot treatments for Experiment I, and small letters mark significant differences for Experiment II (all comparisons: two way ANOVA, Tukey-Kramer HSD, $P<0.001)$.

warm and the reverse DVM treatments (Fig. 3). In Experiment II, burbot showed the best performance in the medium and in the DVM treatments (two-way AnOva, Tukey-Kramer HSD, $P<0.001$ ), while performance did not differ significantly between the warm, reverse DVM and cold treatments. The performance of burbot in the DVM treatment increased with age (pair Expt I to II (pair wise $t$-test, $P<0.01$ ).

\section{Discussion}

Several studies have investigated the behaviour and ecology of larval, juvenile and adult burbot (Ryder \& Pesendorfer, 1992; Wang \& Appenzeller, 1998; Fischer, 1999; Tolonen, Kjellman \& Lappalainen, 1999; Hofmann \& Fischer, 2001; McPhail \& Paragamian, 2000; Dixon \& Vokoun, 2009), but none has evaluated the consequences for survival and growth of larvae in the field. In contrast to former studies on energetic advantages of DVM in fish that focussed only on growth rates under cold and cyclic temperature regimes (Neverman \& Wurtsbaugh, 1994), or on daily food rations (Biette \& Geen, 1980), we investigated for the first time the relative advantages of DVM behaviour when compared to alternative temperature regimes in terms of growth rate combined with survival. We focussed on the hypothesis that DVM is 
an adaptation optimising the bioenergetic efficiency of this cold stenotherm in the pelagic zone of a stratified deep pre-alpine lake. We found that the mortality risk of young burbot differed considerably between the possible migration strategies simulated in the experiments. In nature, the main factors causing mortality of larvae are (i) starvation because of a mismatch between the gape size of larvae and the body size of their planktonic prey, (ii) predation by larger fish or other animals and (iii) energetic inefficiencies because of extreme temperatures (Hunter, 1980). In our experiments, the same prey type of constant size range was fed in excess once per day throughout, so that starvation caused by gape limitation can be excluded. Furthermore, there was no predation. The most likely reason for differences in survival is the different temperature conditions and their consequences for burbot metabolism. Therefore, we decided to combine temperature-dependent survival and growth rate into one measure that could be used to characterise the effect of the different behaviours on burbot performance.

In the warm epilimnion of Lake Constance, larval and early-juvenile burbot feed from dusk until dawn (Probst \& Eckmann, 2009b). The burbot could simply remain in the epilimnion between bouts of feeding. However, the results of the warm treatment in the present experiments suggest that the survival of burbot would be severely reduced, at least during the larval stage, when almost all individuals perished (Fig. 1). Burbot apparently undergo a shift in temperature tolerance during their transition from the larval to the early-juvenile phase, because mortality decreased considerably after metamorphosis (Fig. 1), though it remained higher in warmer water than in all other treatments. This shift in temperature tolerance might be an adaptation to life in the permanently warm littoral zone, where burbot spend the summer, having shifted from their early pelagic existence to a benthic life style some weeks after metamorphosis (Hofmann \& Fischer, 2002). Even though the growth recorded in the warm water was the highest of all treatments in both experiments, performance was clearly inferior to that of fish in the medium temperature and DVM treatments.

Another option for burbot in the pelagic zone is to stay permanently below the thermocline, a strategy simulated by the cold treatment. Fish in this group exhibited the lowest mortality and were very inactive, which might save energy. Among other gadiform fish, the energetic benefits of staying in cooler water have been shown for cod, where oxygen consumption and heart rate during swimming increase with rising temperature (Claireaux et al., 1995). Despite these potential energy savings, however, burbot in the cold treatment recorded the lowest growth rates in both experiments (Table 2). This agrees with an earlier study showing that young burbot require temperatures of at least $8{ }^{\circ} \mathrm{C}$ for somatic growth (Shodjai, 1980).

The DVM observed during field studies in Lake Constance (Probst \& Eckmann, 2009b) is probably the best compromise between the behaviours discussed so far, allowing young fish to grow quickly, as in warm water, while having reduced mortality. Shortterm temperature shifts of between 4 and $21^{\circ} \mathrm{C}$ are tolerated by larval burbot without prior adaptation and without any physiological disadvantage (Shodjai, 1980). This temperature range is close to the observed gradient experienced by burbot larvae during DVM in Lake Constance (Probst \& Eckmann, 2009b), and the DVM treatments in the present study were designed to mimic this gradient (Table 1). Mortality in Experiment I amounted to about $60 \%$, which might have been caused by the low tolerance of early burbot larvae to high temperature for several hours, but in Experiment II mortality was much lower and did not differ from that observed in the low and medium temperature treatments.

Growth of burbot under simulated DVM conditions was high and matched that in the medium temperature treatment. In both treatments, burbot experienced nearly the same number of degree-days (the cumulative temperature sum over a diel cycle), yet performance in Experiment I was higher for the medium treatment. In Experiment II, on the other hand, growth rate was higher for the DVM treatment, even though the temperature in the medium treatment raised by about $2{ }^{\circ} \mathrm{C}$ within the last 5 days, but performance did not differ significantly between the treatments. Importantly, however, a medium temperature habitat as simulated in this experiment does not actually exist in a temperature-stratified deep prealpine lake. To live permanently at a temperature of 12 or $13{ }^{\circ} \mathrm{C}$ in Lake Constance, wild burbot would be limited to a thin layer of water within the thermocline, in which the availability of food would be low because of the vertical movement of zooplankton prey (Stich, Pfeiffer \& Maier, 2005). Therefore, since 
permanent residence at the average temperature between epi- and hypolimnion of a deep, pre-alpine lake is not a viable alternative, DVM seems to be the best behaviour for larval and early-juvenile burbot optimising performance as a trade off between growth and survival.

Additionally, the timing of DVM seems to be important, as mortality in the reverse DVM treatments was among the highest observed in both experiments. Furthermore, the low growth achieved by burbot in the reverse DVM treatment suggests that an energetic advantage can be gained by feeding in the warm epilimnion from dusk until dawn and then retreating to cold water during nonfeeding hours, but not by the opposite migration pattern. Consequently, the overall performance of burbot in the reverse DVM treatment was about as low as that in the cold and warm treatments (Fig. 3).

The bioenergetic advantage of DVM in the early life stages of burbot, as demonstrated in this study, may not be the only ultimate factor selecting for this particular behaviour. At least two other factors might be involved in driving DVM, namely the vertical migration of burbot prey and the activity of predators in the epilimnion during day. These two hypotheses are not mutually exclusive with that of optimising energetic efficiency, because they select for the same migration pattern, whereby burbot occupy the hypolimnion by day and visit the epilimnion only during darkness. Thus, the DVM as performed by young burbot may serve several complementary functions, maximising food intake, optimising the bioenergetic budget and reducing predation risk. A similar multifactorial basis for DVM has recently been described for vendace (Coregonus albula Linnaeus) by Mehner et al. (2007).

Burbot select copepods as prey (Ghan \& Sprules, 1993), and copepods are known to migrate vertically (Lampert \& Taylor, 1985). Thus, to maintain access to this food source, burbot are obliged to migrate too. The evening ascent to the epilimnion and the morning descent to the hypolimnion represent two windows of opportunity for feeding on vertically migrating prey for larval and early-juvenile burbot in Lake Constance (Probst \& Eckmann, 2009b), although digestion in larval burbot is strongly reduced below $8{ }^{\circ} \mathrm{C}$ (Shodjai, 1980). Field samples have indeed shown that larval burbot feed mainly at dusk, so that food will be digested during the night in the warm epilimnion
(Probst \& Eckmann, 2009b). Previous experiments have shown that larval burbot stopped feeding after $1 \mathrm{~h}$, and gut evacuation was complete after 16-24 h at $12{ }^{\circ} \mathrm{C}$ (Donner, unpublished data), which is close to the feeding pattern observed in the field. This observation supports the foraging efficiency hypothesis.

The predator avoidance hypothesis may be only partly supported by the available data, but it is not contradicted any available evidence. Probst (2008) suggested that DVM during the early life stages of burbot might be genetically fixed, representing a response to predation that occurred in the evolutionary past. This suggestion was based on field data that could not demonstrate any predation by pelagic fish species on larval or early-juvenile burbot. Potential predators in the pelagic zone of Lake Constance are whitefish (Coregonus lavaretus Linnaeus) and Eurasian perch (Perca fluviatilis Linnaeus). Whitefish are present in the pelagic zone throughout the year, but they stay close to the surface only in early spring (Thomas, Rösch \& Eckmann, 2010). Later in the year, when whitefish occupy deeper water, predation on young burbot would be possible only during the short time windows at dusk and at dawn, when burbot ascend and descend through the depth range occupied by the whitefish.

In addition to whitefish, young-of-the-year perch may prey on burbot. Eurasian perch hatch later than burbot. But, because of their rapid growth, they overtake burbot during early summer (Probst \& Eckmann, 2009a) and become potential predators. Piscivorous behaviour is well described for Eurasian perch, where fast-growing young become predators of other fish, e.g. cyprinids or their conspecifics in their first year (Borcherding, 2006). The visually oriented feeding behaviour and diurnal activity of Eurasian perch (Schleuter \& Eckmann, 2006), however, makes nocturnal predation on burbot highly unlikely, and in fact, it has never yet been observed. Detecting predation on larval fish through the analysis of stomach contents from field samples is extremely difficult. For yellow perch (Perca flavescens Mitchell), Legler et al. (2010) observed a digestion time of $5 \mathrm{~h}$, after which no remains of consumed larvae were found in the predators' stomachs. Failure to detect predation on larval fish in the field can, therefore, neither definitively refute nor support the predator avoidance hypothesis. In the case of young burbot, the observed DVM pattern matches a migration behaviour that is to be expected 
when there is a risk of predation in the epilimnion, and hence, we consider the predator avoidance hypothesis to be partly supported by the data.

The observed increase in DVM amplitude (Probst \& Eckmann, 2009b) might be linked to the young burbots' shift from a pelagic to a benthic way of life. In this sense, it has been interpreted as the fish locating the lake bed, from where the juvenile burbot begin their profundal migration towards the littoral zone (Fischer, 1999; Miler \& Fischer, 2004), in a manner similar to the behaviour of other gadoids (Bromley \& Kell, 1999). The proximate reason for the increasing amplitude of DVM might be increasingly negative buoyancy as the fish grow. In fact, negative buoyancy and higher swimming activity was observed in the early-juveniles at the end of the present experiments, whereas the larval burbot seemed to be perfectly buoyant and showed little or no swimming activity except that associated with feeding. An increase in specific gravity during larval development has also been reported for cod (Gadus morhua Linnaeus) by Saborido-Rey, Kjesbu \& Thorsen (2003). Negative buoyancy might increase the amplitude of DVM if fish are less active after feeding, such that consequent sinking in the water column is not fully compensated by swimming activity.

\section{Acknowledgments}

We thank Joachim Böhler and Alfred Sulger for providing the spawners. Special thanks to Myriam Schmid for her help raising the larvae and thanks to Martin Wolf for his help during the setup of the recirculation system. Jens-Peter Herrmann provided useful information for building the system and designing the experiment. Hendrik Wocher assisted with his experience during the breeding of the burbot. Amy-Jane Beer corrected the English. This study was carried out within the Collaborative Research Center 454 "Littoral zone of Lake Constance" funded by the Deutsche Forschungsgemeinschaft.

\section{References}

Adams C.F., Foy R.J., Kelley J.J. \& Coyle K.O. (2009) Seasonal changes in the diel vertical migration of walleye pollock (Theragra chalcogramma) in the northern Gulf of Alaska. Environmental Biology of Fishes, 86, 297-305.
Appenzeller A.R. \& Leggett W.C. (1995) An evaluation of light-mediated vertical migration of fish based on hydroacoustic analysis of the diel vertical movements of rainbow smelt (Osmerus mordax). Canadian Journal of Fisheries and Aquatic Sciences, 52, 504-511.

Biette R.M. \& Geen G.H. (1980) Growth of underyearling Sockeye salmon (Oncorhynchus nerka) under constant and cyclic temperatures in relation to live zooplankton ration size. Canadian Journal of Fisheries and Aquatic Sciences, 37, 203-210.

Borcherding J. (2006) Prey or predator: $0+$ perch (Perca fluviatilis) in the trade-off between food and shelter. Environmental Biology of Fishes, 77, 87-96.

Brett J.R. (1971) Energetic responses of salmon to temperature - study of some thermal relations in physiology and freshwater ecology of sockeye salmon (Oncorhynchus nerka). American Zoologist, 11, 99-113.

Bromley P.J. \& Kell L.T. (1999) Vertical migration and spatial distribution of pelagic 0-group gadoids (cod, haddock, whiting, and Norway pout) prior to and during settlement in the North Sea. Acta Adriatica, 40, 7-17.

Cech M., Kratochvil M., Kubecka J., Drastik V. \& Matena J. (2005) Diel vertical migrations of bathypelagic perch fry. Journal of Fish Biology, 66, 685-702.

Claireaux G., Webber D.M., Kerr S.R. \& Boutilier R.G. (1995) Physiology and behavior of free-swimming Atlantic cod (Gadus morhua) facing fluctuating temperature conditions. Journal of Experimental Biology, 198, 49-60.

Clark D.S. \& Green J.M. (1991) Seasonal-variation in temperature preference of juvenile Atlantic cod (Gadus morhua), with evidence supporting an energetic basis for their diel vertical migration. Canadian Journal of Zoology, 69, 1302-1307.

Clark C.W. \& Levy D.A. (1988) Diel vertical migrations by juvenile sockeye salmon and the antipredation window. American Naturalist, 131, 271-290.

De Robertis A., Jaffe J.S. \& Ohman M.D. (2000) Sizedependent visual predation risk and the timing of vertical migration in zooplankton. Limnology and Oceanography, 45, 1838-1844.

Dixon C.J. \& Vokoun J.C. (2009) Burbot resource selection in small streams near the southern extent of the species range. Ecology of Freshwater Fish, 18, 234-246.

Dupont N., Klevjer T.A., Kaartvedt S. \& Aksnes D.L. (2009) Diel vertical migration of the deep-water jellyfish Periphylla periphylla simulated as individual responses to absolute light intensity. Limnology and Oceanography, 54, 1765-1775.

Eckmann R. \& Imbrock F. (1996) Distribution and diel vertical migration of Eurasian perch (Perca fluviatilis 
L.) during winter. Annales Zoologici Fennici, 33, 679686.

Fischer P. (1999) Otolith microstructure during the pelagic, settlement and benthic phases in burbot. Journal of Fish Biology, 54, 1231-1243.

Ghan D. \& Sprules W.G. (1993) Diet, prey selection, and growth of larval and juvenile burbot Lota lota (L). Journal of Fish Biology, 42, 47-64.

Helfman G.S. (1993) Fish behavior by day, night and twilight. In: The Behaviour of Teleost Fish. (Ed T.J. Pitcher), pp. 366-387. The Johns Hopkins University Press, Baltimore.

Hirning M. (2006) Laichgebiete und Laichwanderverhalten von Trüschen (Lota lota) im Bodensee. Magister Thesis, University of Freiburg, Freiburg.

Hofmann N. \& Fischer P. (2001) Seasonal changes in abundance and age structure of burbot Lota lota (L.) and stone loach Barbatula barbatula (L.) in the littoral zone of a large pre-alpine lake. Ecology of Freshwater Fish, 10, 21-25.

Hofmann N. \& Fischer P. (2002) Temperature preferences and critical thermal limits of burbot: implications for habitat selection and ontogenetic habitat shift. Transactions of the American Fisheries Society, 131, 1164-1172.

Hofmann N. \& Fischer P. (2003) Impact of temperature on food intake and growth in juvenile burbot. Journal of Fish Biology, 63, 1295-1305.

Hrabik T.R., Jensen O.P., Martell S.J.D., Walters C.J. \& Kitchell J.F. (2006) Diel vertical migration in the Lake Superior pelagic community. I. Changes in vertical migration of coregonids in response to varying predation risk. Canadian Journal of Fisheries and Aquatic Sciences, 63, 2286-2295.

Hunter J.R. (1980) The feeding behavior and ecology of marine fish larvae. In: Fish Behavior and its Use in Capture and Culture of Fishes (Eds J.E. Bardach, J.J. Magnuson, R.C. May \& J.M. Reinhart), pp. 287-330. International Center for Living Aquatic Resources Management, Manila, Philippines.

Hurst T.P., Cooper D.W., Scheingross J.S., Seale E.M., Laurel B.J. \& Spencer M.L. (2009) Effects of ontogeny, temperature, and light on vertical movements of larval Pacific cod (Gadus macrocephalus). Fisheries Oceanography, 18, 301-311.

Lampert W. \& Taylor B.E. (1985) Zooplankton grazing in an eutrophic lake: implications of diel vertical migration. Ecology, 66, 68-82.

Legler N.D., Johnson T.B., Heath D.D. \& Ludsin S.A. (2010) Water temperature and prey size effects on the rate of digestion of larval and early juvenile fish. Transactions of the American Fisheries Society, 139, 868-875.

Levy D.A. (1987) Review of the ecological significance of diel vertical migrations by juvenile sockeye salmon
(Oncorhynchus nerka). Special Publications of the Canadian Journal of Fisheries \& Aquatic Sciences, 96, 44-52.

McPhail J.D. \& Paragamian V.L. (2000) Burbot biology and life history. In: Burbot biology, ecology, and management (Eds V.L. Paragamian \& D.H. Willis), pp. 11-23, American Fisheries Society, Fisheries Management Section Publication Number 1, Bethesda, Maryland.

Mehner T., Kasprzak P. \& Hölker F. (2007) Exploring ultimate hypotheses to predict diel vertical migrations in coregonid fish. Canadian Journal of Fisheries and Aquatic Sciences, 64, 874-886.

Miler O. \& Fischer P. (2004) Distribution and onshore migration behaviour of burbot larvae in Lake Constance, Germany. Journal of Fish Biology, 64, 176-185.

Neverman D. \& Wurtsbaugh W.A. (1994) The thermoregulatory function of diel vertical migration for a juvenile fish, Cottus extensus. Oecologia, 98, 247-256.

Persson L. (1982) Rate of food evacuation in roach (Rutilus rutilus) in relation to temperature, and the application of evacuation rate estimates for studies on the rate of foodconsumption. Freshwater Biology, 12, 203-210.

Probst W.N. (2008) New insights into the ecology of perch Perca fluviatilis L. and burbot Lota lota (L.) with special focus on their pelagic life-history. Doctoral Thesis (Dr. rer. nat.), University of Konstanz, Konstanz. (http:// nbn-resolving.de/urn:nbn:de:bsz:352-opus-72670).

Probst W.N. \& Eckmann R. (2009a) Diet overlap between young-of-the-year perch, Perca fluviatilis L., and burbot, Lota lota (L.), during early life-history stages. Ecology of Freshwater Fish, 18, 527-537.

Probst W.N. \& Eckmann R. (2009b) The influence of light on the diel vertical migration of young-of-the-year burbot Lota lota in Lake Constance. Journal of Fish Biology, 74, 150-166.

Ricker W.E. (1979) Growth rates and models. In: Fish Physiology, Vol 8, (Eds W.S. Hoar, D.J. Randall \& J.R. Brett), pp. 677-743, Academic Press, New York.

Ryder R.A. \& Pesendorfer J. (1992) Food, growth, habitat, and community interactions of young-of-the-year burbot, Lota lota L., in a Precambrian shield lake. Hydrobiologia, 243/244, 211-227.

Saborido-Rey F., Kjesbu O.S. \& Thorsen A. (2003) Buoyancy of Atlantic cod larvae in relation to developmental stage and maternal influences. Journal of Plankton Research, 25, 291-307.

Schabetsberger R., Brodeur R., Ciannelli L., Napp J.M. \& Swartzman G.L. (2000) Diel vertical migration and interaction of zooplankton and juvenile walleye pollock (Theragra chalcogramma) at a frontal region near the Pribilof Islands, Bering Sea. ICES Journal of Marine Science, 57, 1283-1295.

Scheuerell M.D. \& Schindler D.E. (2003) Diel vertical migration by juvenile sockeye salmon: empirical 
evidence for the antipredation window. Ecology, 84, 1713-1720.

Schleuter D. \& Eckmann R. (2006) Competition between perch (Perca fluviatilis) and ruffe (Gymnocephalus cernuus): the advantage of turning night into day. Freshwater Biology, 51, 287-297.

Schmidt-Nielson K. (1997) Animal Physiology - Adaptation and Environment. Cambridge University Press, Cambridge.

Schneider J., Lelek A. \& Korte E. (2002) Wiedereinbürgerung der Quappe (Lota lota) in der Ruhr (NRW) durch die Ruhrfischereigenossenschaft, Essen. In: Fisch des Jahres 2002, Die Quappe (Lota lota) (Ed. VDSF e.V.), pp. 5-19, VDSF, Offenbach am Main.

Semyalo R., Nattabi J.K. \& Larsson P. (2009) Diel vertical migration of zooplankton in a eutrophic bay of Lake Victoria. Hydrobiologia, 635, 383-394.

Shodjai F. (1980) Entwicklungs-, stoffwechsel- und ernaehrungsphysiologische Untersuchungen an der Aalquappe (Lota lota L.) unter Beruecksichtigung ihrer Eignung als Kulturfisch. Doctoral Thesis, University of Kiel, Kiel.

Sims D.W., Wearmouth V.J., Southall E.J. et al. (2006) Hunt warm, rest cool: bioenergetic strategy underlying diel vertical migration of a benthic shark. Journal of Animal Ecology, 75, 176-190.

Sommer U. \& Gliwicz Z.M. (1986) Long range vertical migration of Volvox in tropical lake Cahora Bassa (Mozambique). Limnology \& Oceanography, 31, 650653.

Stich H.B., Pfeiffer M. \& Maier G. (2005) Zooplankton communities in a large prealpine lake, Lake Constance: comparison between the Upper and the Lower Lake. Journal of Limnology, 64, 129-138.
Thomas G., Rösch R. \& Eckmann R. (2010) Seasonal and long-term changes in fishing depth of Lake Constance whitefish. Fisheries Management and Ecology, 17, 386393.

Tolonen A., Kjellman J. \& Lappalainen J. (1999) Diet overlap between burbot (Lota lota (L.)) and whitefish (Coregonus lavaretus (L.)) in a subarctic lake. Annales Zoologici Fennici, 36, 205-214.

Voss R., Schmidt J.O. \& Schnack D. (2007) Vertical distribution of Baltic sprat larvae: changes in patterns of diel migration? ICES Journal of Marine Science, 64, 1-7.

Wang N. \& Appenzeller A. (1998) Abundance, depth distribution, diet composition and growth of perch (Perca fluviatilis) and burbot (Lota lota) larvae and juveniles in the pelagic zone of Lake Constance. Ecology of Freshwater Fish, 7, 176-183.

Weng K.C. \& Block B.A. (2004) Diel vertical migration of the bigeye thresher shark (Alopias superciliosus), a species possessing orbital retia mirabilia. Fishery Bulletin, 102, 221-229.

Wurtsbaugh W.A. \& Neverman D. (1988) Post-feeding thermotaxis and daily vertical migration in a larval fish. Nature, 333, 846-848.

Yamashita Y., Kitagawa D. \& Aoyama T. (1985) Diel vertical migration and feeding rhythm of the larvae of the Japanese sand-eel Ammodytes personatus. Bulletin of the Japanese Society of Scientific Fisheries, 51, 1-5.

Young J.D. \& Yan N.D. (2008) Modification of the diel vertical migration of Bythotrephes longimanus by the cold-water planktivore, Coregonus artedi. Freshwater Biology, 53, 981-995. 